\title{
Neonatal mouse gonocyte proliferation assayed by an in vitro clonogenic method
}

\author{
S. Hasthorpe, S. Barbic, P. J. Farmer and J. M. Hutson \\ F Douglas Stephens Surgical Research Laboratory, Royal Children's Hospital, Flemington Road, \\ Parkville, Victoria 3052, Australia
}

\begin{abstract}
Survival and proliferation of mouse gonocytes was studied using a single cell clonogenic assay in vitro. The effect of growth factors and extracellular matrix on clonogenic development was quantitated. Fundamental requirements for growth of neonatal gonocytes included addition of fetal calf serum and coating culture wells with collagen IV alone or with added fibronectin. After 4-5 days, colonies ranged in size from four to $>128$ cells, and some contained very elongated cells indicating migratory behaviour. Soluble stem cell factor did not have any effect on clonogenicity, although STO (subline of SIM mouse fibroblasts) cells, which produce membrane-bound stem cell factor, reduced colony formation from $79 \pm 5.9 \%$ to $20 \pm 3.3 \%$ without added growth factor. The majority of gonocytes and type A spermatogonia express the c-kit receptor according to in situ hybridization studies. However, the results indicate that the receptor may not be functional in neonatal gonocytes and their immediate progeny. The current assay for gonocytes can be extended to test new growth factors or proliferation-inducing agents directly, as well as to study cell-cell interactions. This assay and long-term propagation of neonatal germ cells will provide the much needed resources to enable greater understanding of the early development of germ cells.
\end{abstract}

\section{Introduction}

Germ cells segregate from the somatic cell lineage during development and are derived from ectoderm and arise in the epiblast (McLaren, 1983). The first recognizable germ cell, the primordial germ cell, migrates to the developing gonad. In males, it subsequently undergoes mitotic arrest at about 14.5 days post coitum (McLaren, 1985) and does not re-enter mitosis until after birth. The quiescent primordial germ cell at birth is often referred to as a gonocyte or prospermatogonia. Mitosis resumes in the first few days after birth along with migration from the centre of the seminiferous cord to the periphery, thereby coming into close contact with the basement membrane and Sertoli cells (Clermont and Perey, 1957).

Although gonocytes and their immediate progeny have been studied extensively in vivo, development of a culture system for these germ cells is necessary for further progress. Observations from studies in vivo need to be applied to an in vitro environment to achieve this. In vivo, a proportion of gonocytes elongate and form pseudopod-like processes that allow active migration of the gonocyte; formation of these processes has also been observed in vitro (McGuinness and Orth, 1992a). Movement to the periphery of the cord and contact with the basement membrane is an interaction necessary for gonocyte differentiation to the type A

Received 4 September 1998. spermatogonial stage. The seminiferous tubule basement membrane is composed of laminin and collagen IV is located in the interstitial region (Sawada and Yazama, 1994). Other extracellular matrix (ECM) molecules found in the male gonad include fibronectin, proteoglycans and collagens I, II and IV (Pelliniemi et al., 1984; Skinner et al., 1985; Paranko, 1987; Gelly et al., 1989). The effect of ECM on gonocyte development and survival has been studied in vitro using coculture of Sertoli cells and gonocytes (Orth and McGuinness, 1991; Dissel-Emiliani et al., 1993). An additional complex interaction in germ cell maturation involves gonocytes and cells of the testis microenvironment, in particular Sertoli cells. Co-culture experiments indicate that paracrine regulation of germ cell proliferation and differentiation occurs in vivo and in vitro (Orth and Boehm, 1990; Orth and McGuinness, 1991; Dissel-Emiliani et al., 1993; De Miguel et al., 1996).

Growth factors and their receptors are actively expressed in the embryonic and neonatal phases of testicular development (Kierszenbaum, 1994; Orth et al., 1996; Loveland and Schlatt, 1997). However, there is some disparity in the detection of c-Kit at the gonocyte or undifferentiated type A spermatogonia stages, although there is agreement that differentiating spermatogonia express c-Kit uniformly. This controversy may be due in part to an innate difference in mice and rats, since Orth et al. (1996, 1997) and Munsie et al. (1997) reported c-Kit mRNA and protein expression in rat gonocytes. In mice, the c-Kit protein 
Table 1. c-kit in situ hybridization on mouse neonatal testis

\begin{tabular}{llccc}
\hline Age (days) & Type of cell & $\begin{array}{c}\text { Grains per } \\
\text { cell antisense }\end{array}$ & $\begin{array}{c}\text { Grains per } \\
\text { cell sense control }\end{array}$ & $\begin{array}{c}\text { Percentage of } \\
\text { positive ceils* }\end{array}$ \\
\hline 1 & Gonocyte & $11.7 \pm 0.8$ & $4.6 \pm 0.2$ & $77 \pm 3$ \\
3 & Gonocyte & $16.6 \pm 1.9$ & $4.8 \pm 0.1$ & $88 \pm 2$ \\
7 & Type A spermatogonia & $20.8 \pm 1.9$ & $4.8 \pm 0.3$ & $92 \pm 1$ \\
& Type A spermatogonia & $34.2 \pm 5.3$ & $3.8 \pm 0.2$ & $100 \pm 0.4$ \\
\hline
\end{tabular}

Values are mean $\pm \mathrm{SEM}, n=5$.

*Percentage of cells treated with antisense with a greater number of mean grains per cell than the sense control.

has not been detected in gonocytes (Yoshinago et al., 1991). In the present study, a sensitive in situ hybridization method was used to detect c-Kit mRNA in newborn gonocytes.

Co-culture experiments indicate that the neonatal phase of germ cell maturation is associated with highly specific and finely regulated controlling factors. However, the genes involved have yet to be clearly defined. An in vitro environment in which gonocytes can be manipulated directly is required to understand better the molecules that are involved. The aim of the present study was to develop a clonogenic culture system in which gonocytes are selected and the formation of germ cell colonies is assayed. Micromanipulation techniques were used to isolate gonocytes in a pure form for incubation and assay. In the long term, in vitro cultures of germ cells will enable access to sufficiently high numbers of cells to enable molecular analysis of the genes that regulate the early stages of germ cell differentiation.

\section{Materials and Methods}

\section{Mice}

Inbred HSD OLA:ICR Swiss mice were used throughout the study and the day of birth was denoted as day 1 . In the experiments involving culture on STO cell underlays, the ROSA 26 mouse strain was used as a source of gonocytes (Friedrich and Soriano, 1991).

\section{In situ hybridization}

The SP71 vector carrying plasmid DNA consisting of a $900 \mathrm{bp}$ c-kit PvuII fragment was linearized with Xho1 for antisense and with EcoR1 for sense riboprobes. Riboprobes were generated and radiolabelled by incorporation of ${ }^{35}[\mathrm{~S}]$ cytidine $5^{\prime}$-triphosphate (CTP) $(100 \mu \mathrm{Ci}$ at $1200 \mathrm{Ci}$ $\mathrm{mmol}^{-1}$ ) according to Russo et al. (1994) and Edmondson et al. (1995). A Ribocore kit (Promega, Sydney) was used to transcribe the riboprobes from linearized plasmid. Tissues were fixed in $10 \%(\mathrm{v} / \mathrm{v})$ formalin and sections prepared on aminoalkysilane-coated slides by conventional methods. Wax was removed from the sections and they were dehydrated, treated with the enzyme pronase $\mathrm{E}\left(125 \mu \mathrm{g} \mathrm{ml}^{-1}\right)$ for $10 \mathrm{~min}$ at $37^{\circ} \mathrm{C}$, and fixed in $4 \%(\mathrm{w} / \mathrm{v})$ paraformaldehyde in PBS for $10 \mathrm{~min}$. Labelled riboprobes, at a concentration of $5 \times 10^{5}$ c.p.m. probe in $25 \mu \mathrm{l}$ hybridization buffer containing
$50 \%(\mathrm{v} / \mathrm{v})$ formamide per slide, were heated to $85^{\circ} \mathrm{C}$ and placed on slides. Coverslips were applied and the slides were incubated at $55^{\circ} \mathrm{C}$ overnight. After hybridization, slides were washed in $50 \%$ formamide with $2 \times$ SSC (sodium tri-sodium citrate) at $55^{\circ} \mathrm{C}$ followed by RNAse digestion for $1 \mathrm{~h}$ at $37^{\circ} \mathrm{C}$, a wash in $2 \times$ SSC, dehydration and air drying. Slides were dipped in LM-2 emulsion (Amersham, Castle Hill), and developed in D19 developer (Kodak, Melbourne) after 3 weeks exposure at $4^{\circ} \mathrm{C}$. The slides were stained in Mayer's haematoxylin and mounted in DPX (BDH, Poole).

Grain counts were carried out on both antisense and sense controls. All grains overlying the nuclei and on the perimeter were counted. A total of 100 of each type of cell was analysed for the various time points and a mean value \pm SE was calculated ( $n=5$ mice). The percentage of positive cells was determined by subtracting the mean sense value from the antisense value on corresponding testis sections. For each group, the mean value \pm SE was calculated (Table 1).

\section{Immunofluorescence of ECM}

Newborn testes were fixed in $10 \%(\mathrm{v} / \mathrm{v})$ buffered formalin and processed for wax embedding. Fibronectin staining involved an unmasking step for $13 \mathrm{~min}$ at $37^{\circ} \mathrm{C}$ in $0.1 \%(\mathrm{w} / \mathrm{v})$ trypsin in PBS followed by a 10 min blocking step using $1-5 \%$ sheep serum with $0.1 \%$ BSA. A rabbit anti-fibronectin antibody (DAKO Corporation, Sydney) was diluted 1:200, incubated with sections for $1 \mathrm{~h}$ at room temperature and then washed from slides with three changes of PBS. A fluourescent sheep anti-rabbit affinity purified Ig conjugated to fluorescine isothiocyanate (FITC) diluted 1:200 was used to label tissues for $30 \mathrm{~min}$ at room temperature. The same procedure was carried out for laminin and collagen IV with omission of the unmasking step. The antibodies were rabbit anti-laminin (Sigma Chemical Co., St Louis, MO) diluted 1:30 and mouse anti-human collagen IV (DAKO) diluted 1:50. Sections were viewed on an Orthoplan microscope with fluorescent attachments. These experiments were carried out to confirm earlier reports (Sawada and Yazama, 1994; Skinner et al., 1985; Pelliniemi et al., 1984) and data are not shown here.

\section{In vitro culture of gonocytes}

Testes were dissected from 10 or more 1-day-old mice and stored in PBS. Enzymic digestion of testes involved a $20 \mathrm{~min}$ 

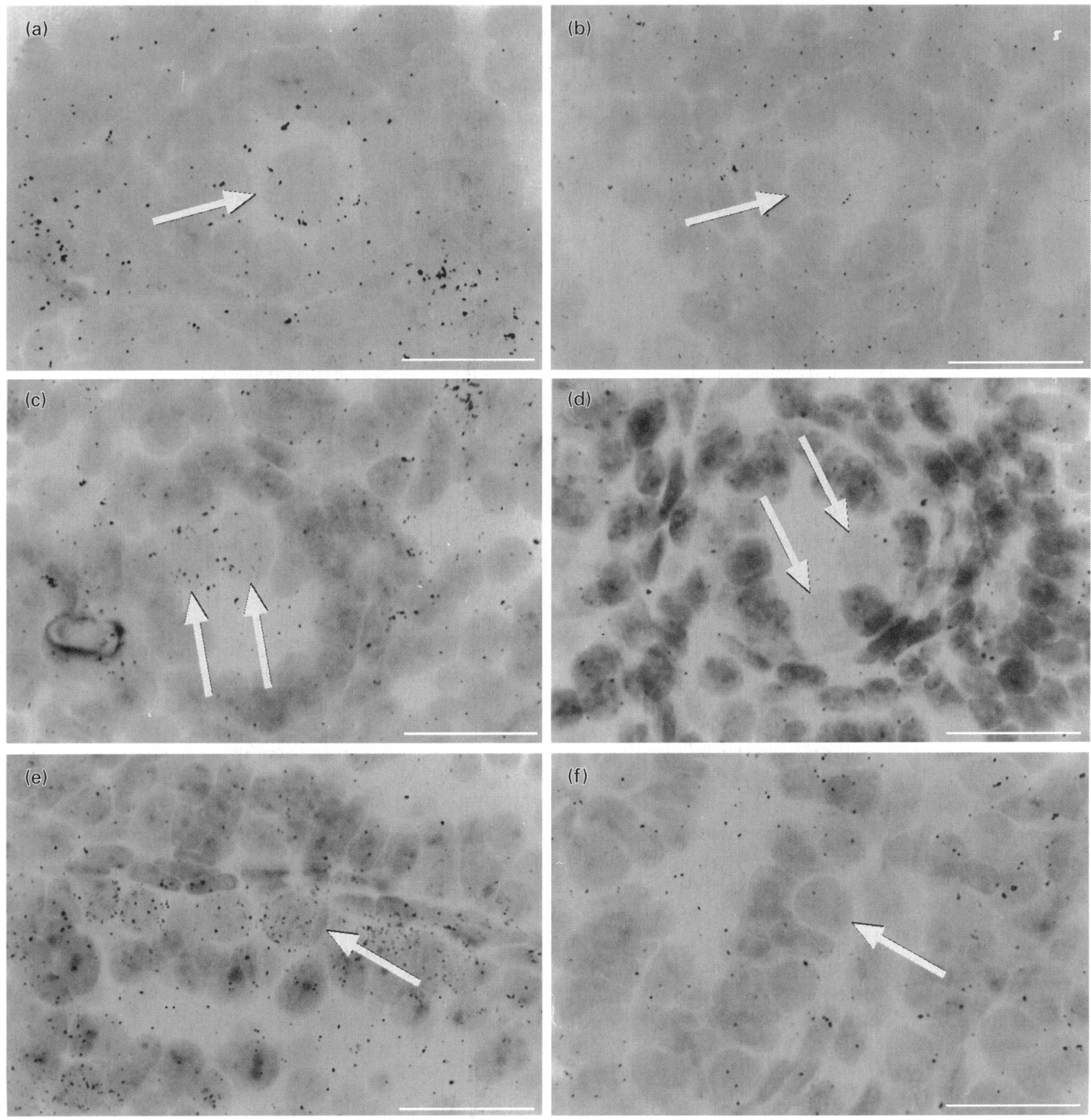

Fig. 1. In situ hybridization using c-kit antisense and sense probes on mouse testis. (a) 1-day-old testis labelled with antisense $c-k i t$ showing autoradiographic grains localized over the gonocyte nucleus and (b) the corresponding sense probe with relatively little labelling associated with the gonocyte. (c) 3-day-old testis showing antisense labelling of a gonocyte and one in transition to a type A spermatogonia and (d) the corresponding sense probe. (e) 7-day-old testis showing labelling of type A spermatogonia adjacent to the base of the seminiferous tubule and (f) the corresponding sense probe. Scale bars represent $25 \mu \mathrm{m}$.

incubation at $37^{\circ} \mathrm{C}$ with a mixture containing hyaluronidase $\left(100 \mu \mathrm{g} \mathrm{ml}^{-1}\right)$, trypsin $\left(100 \mu \mathrm{g} \mathrm{ml}^{-1}\right)$, collagenase $\left(100 \mu \mathrm{g} \mathrm{ml}^{-1}\right)$ and DNase $1\left(5 \mu \mathrm{g} \mathrm{ml}^{-1}\right)$; all enzymes were purchased from Sigma Chemical Co. (St Louis, MO). After washing, the testes they were gently disrupted using a dounce homogenizer with Iscove's modified Dulbecco's medium (IMDM; Gibco BRL, Life Technologies Inc., Grand Island, NY) containing $1 \%(\mathrm{w} / \mathrm{v})$ BSA (Fraction V, Sigma Chemical Co.) on ice. Gonocytes were collected individually using phase-contrast microscopy and a drawn out Pasteur pipette (tip diameter approximately $250 \mu \mathrm{m}$ ). The cells were deposited into a second $60 \mathrm{~cm}$ diameter tissue culture treated Petri dish and single gonocytes were transferred to individual wells of a 96-well microtitre plate containing $150 \mu \mathrm{l}$ culture medium with additives. Gonocyte cloning medium contained IMDM, nucleosides (Robertson, 1985), non-essential amino acids (Gibco BRL), $1 \times 10^{-6} \quad \beta$-mercaptoethanol (Sigma Chemical Co.) and $20 \%$ fetal calf serum (FCS) with growth factors added as indicated below. Microtitre wells were precoated with collagen IV (Collaborative Biomedical 


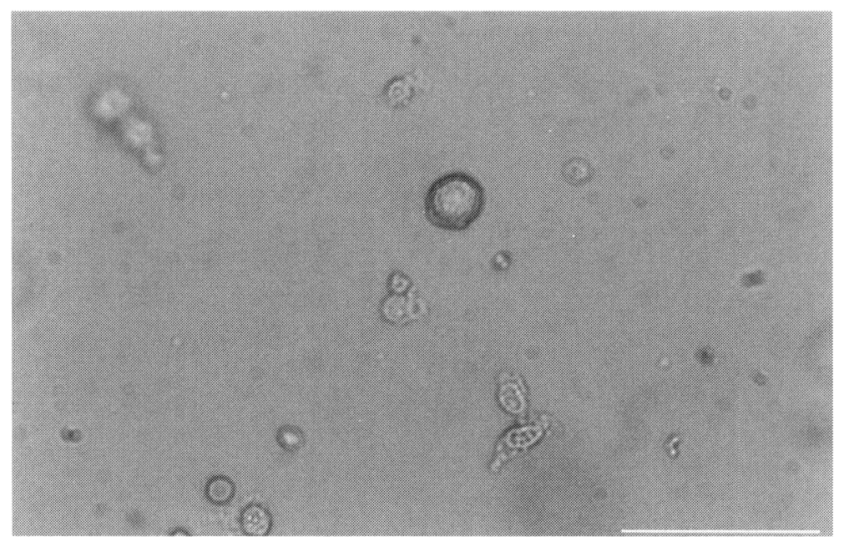

Fig. 2. A single cell suspension obtained by enzyme dissociation of 1-day-old mouse testis in which gonocytes appear as the largest cell type surrounded by somatic cells. Scale bar represents $62.5 \mu \mathrm{m}$.

Products, Becton Dickinson, Bedford, MA) for $1 \mathrm{~h}$ at room temperature, washed with IMDM, incubated with fibronectin ( $5 \mu \mathrm{g} \mathrm{cm}^{-2}$, Boehringer-Mannheim, Melbourne), laminin (5 $\mu \mathrm{g} \mathrm{cm}^{-2}$; Boehringer-Mannheim) or collagen IV (10 $\mu \mathrm{g} \mathrm{cm}^{-2}$; Collaborative Research Products) for $1 \mathrm{~h}$, and the plates were washed and used.

STO cell underlays (Ware and Axelrad, 1972) were made by treating cultures with mitomycin C (10 $\mu \mathrm{g} \mathrm{ml}^{-1}$; Sigma) for $3 \mathrm{~h}$ at $37^{\circ} \mathrm{C}$ and seeding 96-well plates with $2 \times 10^{5}$ cells per well in IMDM with 10\% FCS. The medium was then aspirated and replaced with gonocyte cloning medium. All cultures were incubated at $37^{\circ} \mathrm{C}$ in a humidified $5 \% \mathrm{CO}_{2}: 95 \%$ air atmosphere. A number of growth promoting molecules were tested for their effect on gonocyte colony formation, including rat stem cell factor (SCF, (100 $\mathrm{ng} \mathrm{ml}^{-1}$; Amgen, Thousand Oaks, CA ), platelet-derived growth factor (PDGF bb, $10 \mathrm{ng} \mathrm{ml}^{-1}$; Sigma), leukaemia inhibitory factor (LIF, $5 \mathrm{U} \mathrm{ml}^{-1}$; Amrad Biotech, Australia), oestradiol (2 $\mathrm{mmol} \mathrm{l}^{-1}$; Sigma) and a high affinity oestrogen receptor antagonist, ICI 182,780 (100 $\mathrm{nmol} \mathrm{l}^{-1}$, Tocris Cookson Ltd, Bristol).

An anti-SCF antibody was added to cultures to determine whether serum contained sufficient SCF to stimulate colony formation. Goat anti-mouse SCF was added to culture wells at $160 \mu \mathrm{g} \mathrm{ml}^{-1}$, which represented a 4 - to 40 -fold excess over the $\mathrm{ND}_{50}$ (antibody concentration giving half maximal inhibition of bioactivity of SCF) of $4-40 \mathrm{ng} \mathrm{ml}^{-1}$ (Sigma). Normal marrow-derived mast cells were used as controls to assess the effectiveness of anti-SCF and these cells were cultured as described by Nocka et al. (1990). Mast cells were stained with Alcian blue and test cell aliquots contained $\geq 95 \%$ Alcian blue-positive cells. Proliferating cells were labelled with $\left[6-{ }^{3} \mathrm{H}\right]$ thymidine that had a specific activity of $185 \mathrm{GBq} \mathrm{mmol}^{-1}$ (Amersham Life Science, Castle Hill).

\section{Germ cell nuclear antigen (GCNA-1) immunocytochemical staining}

Paraffin wax sections of testes were prepared as controls and stained according to Enders and May (1994). Colony cells at day 5 day of culture were pooled into a $5 \mathrm{ml}$ tube (Falcon Plastics, Becton Dickinson), fixed in a $1 \%(\mathrm{w} / \mathrm{v})$ paraformaldehyde solution for $10 \mathrm{~min}$, washed, and resuspended in $0.1 \%(\mathrm{v} / \mathrm{v})$ Triton-X100 in PBS. The GCNA-1 antibody (University of Kansas Medical Center, Kansas City, KS) hybridoma supernatant was not diluted and cells were incubated for $30 \mathrm{~min}$ on ice and washed with $0.1 \%(\mathrm{v} / \mathrm{v})$ Triton-X100 in PBS. Anti-mouse $\mathrm{F}\left(\mathrm{ab}^{\prime}\right)_{2}$-fluorescine isothiocyanate conjugate $\left(\mathrm{F}\left(\mathrm{ab}^{\prime}\right)_{2}\right.$-FITC) was added for $30 \mathrm{~min}$ at $4^{\circ} \mathrm{C}$ and the cells were observed under a fluorescence microscope.

\section{Results}

\section{In situ hybridization with c-kit riboprobes}

In situ labelling of gonocytes was observed in 1- and 3day-old testes with a c-kit antisense riboprobe (Fig. 1a,b), and was distinct from labelling in the sense control and in surrounding Sertoli cells (Fig. 1c,d). By day 7, differentiation into type A spermatogonia was complete and these cells also expressed c-kit mRNA (Fig. 1e,f). At day 14, type A spermatogonia continued to express c-kit, although there was a definite lack of expression in primary spermatocytes which are the predominant differentiated cell type (data not shown). Gonocytes and type A spermatogonia prepared for in situ hybridization were quantitated by grain counting for the various ages (Table 1). In all cases, there was a significant difference between antisense and sense controls (Fig. 1a,b). It was observed that $77 \%$ of newborn gonocytes expressed measurable c-kit receptors and had a mean of $11.7 \pm 0.8$ grains per cell.

\section{Clonogenic assay of gonocytes}

Gonocytes can be distinguished from all other somatic cells in the neonatal testis by size, thus micromanipulation was ideal for isolating gonocytes for culture in vitro (Fig. 2). Micromanipulation has the advantage of cell purity and the ability to isolate and transfer an individual cell into a well. The assay was based on depositing one gonocyte per well and detecting one colony per well, and using this to calculate the percentage of positive wells. The higher efficiency of cloning gonocytes was dependent largely upon the presence of an ECM coating (Fig. 3). The presence of collagen IV, fibronectin and laminin in vivo in the basement membrane of newborn mouse seminiferous tubules was confirmed (data not shown). Various ECM combinations were assayed in vitro and collagen IV alone or with added fibronectin was found to give large colony numbers reliably. In addition, the colony size peaked at $>16-64$ cells per colony with collagen IV and $<4-64$ cells for collagen IV with fibronectin (Fig. 3 ). With added laminin or no ECM coating the peak colony size was lower ( $>4-16$ cells per colony). In all subsequent experiments, the wells were coated with collagen IV and fibronectin, unless otherwise stated.

Initiation of the development of a colony from a single gonocyte appeared to occur soon after incubation. After $48 \mathrm{~h}$ 
(a)

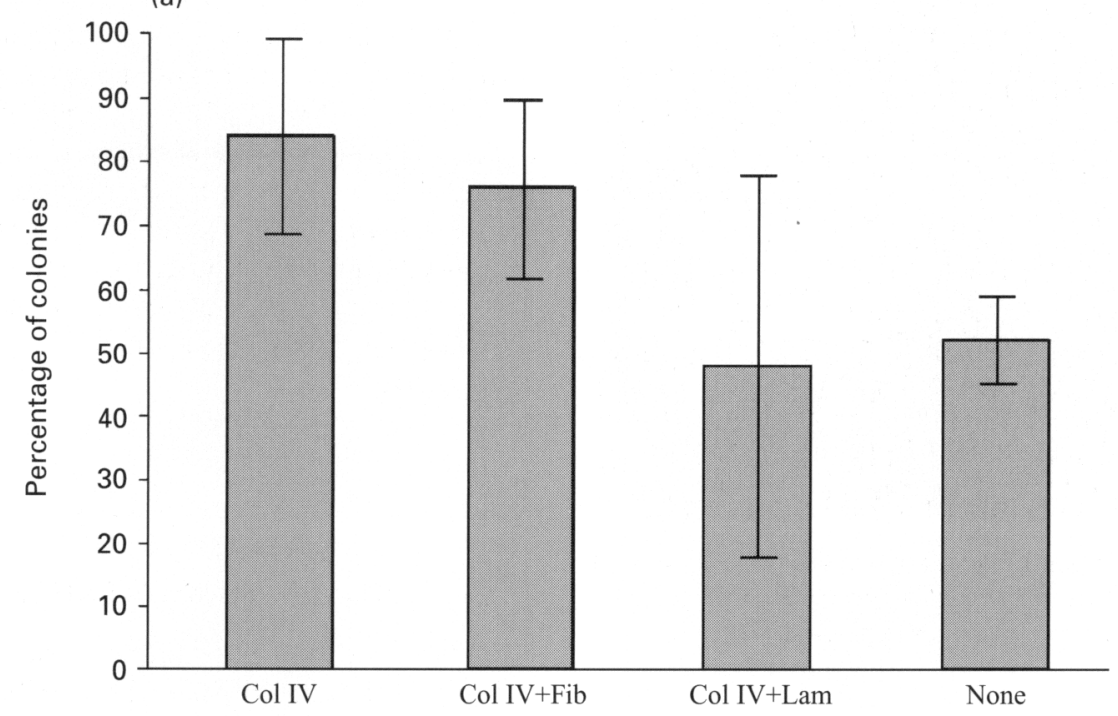

(b)

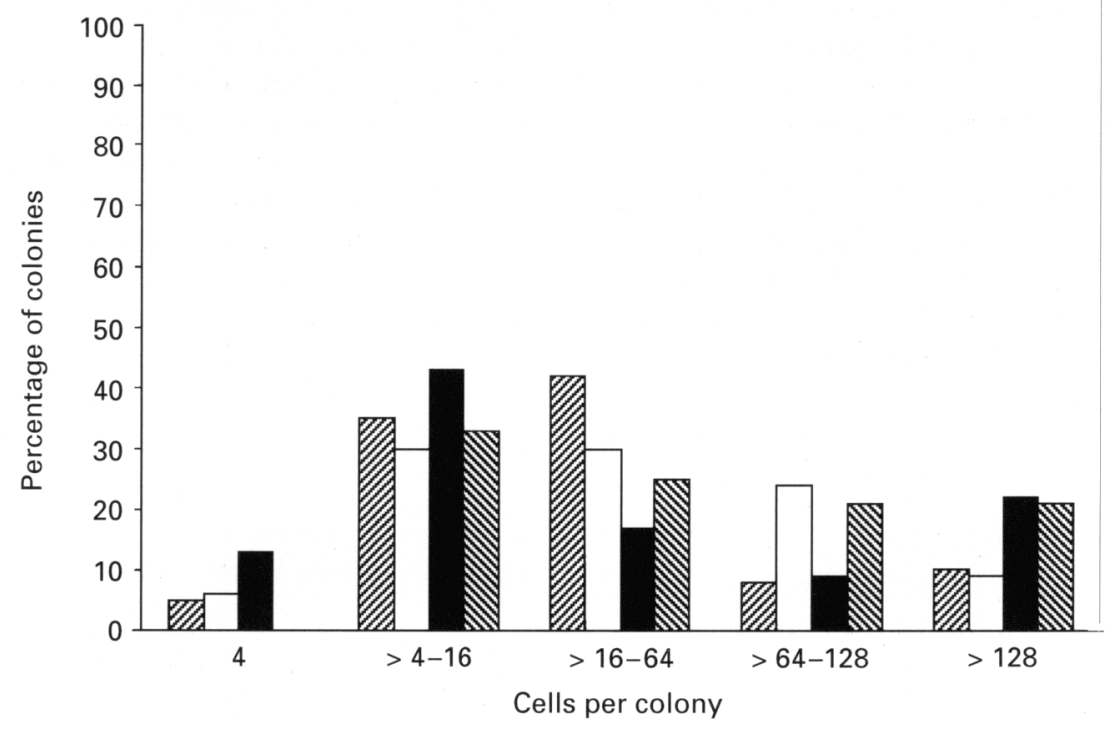

Fig. 3. (a) The percentage of mouse gonocyte-derived colonies formed in 96-well plates coated with collagen IV (Col IV) and fibronectin (Fib), laminin (Lam) or without added growth factors, and cultured for 4-5 days. The mean \pm SD was calculated from cultures over five experiments. (b) Size of colonies in (a) cultured with extracellular matrix components: $\mathbb{Z}$, collagen IV; $\square$, collagen IV and fibronectin; $\boldsymbol{\square}$, collagen IV and laminin; , no added factors.

there were up to 8 cells per colony, and colonies continued to enlarge up to day 5 , at which time they were assayed (Fig. 4). Some of the colonies contained very elongated cells, which may represent a migratory subpopulation (Fig. 5). The growth characteristics of the gonocyte-derived colonies resulted in three basic colony types: compact, dispersed or matrix-associated (Fig. 6). Compact colonies were most numerous $(70 \%)$ and were floating or not firmly attached to the extracellular matrix underlay. Dispersed colonies $(10 \%)$ had a similar appearance, except individual clusters were present that contained fewer cells. It is common for nonadherent types of cell to move about a vessel and establish a dispersed pattern. The matrix-associated colonies $(20 \%)$ were more unusual: a crumpled clear acellular matrix (resembling cellophane) was associated with the cells, some of which were adhered to the outer rim. At this stage, it is not possible to explain this type of cellular growth pattern. Colony cells were routinely stained with GCNA antibody to confirm their germ cell nature (Fig. 7). Viability of cells within colonies was confirmed using $0.04 \%(\mathrm{v} / \mathrm{v})$ trypan blue. 

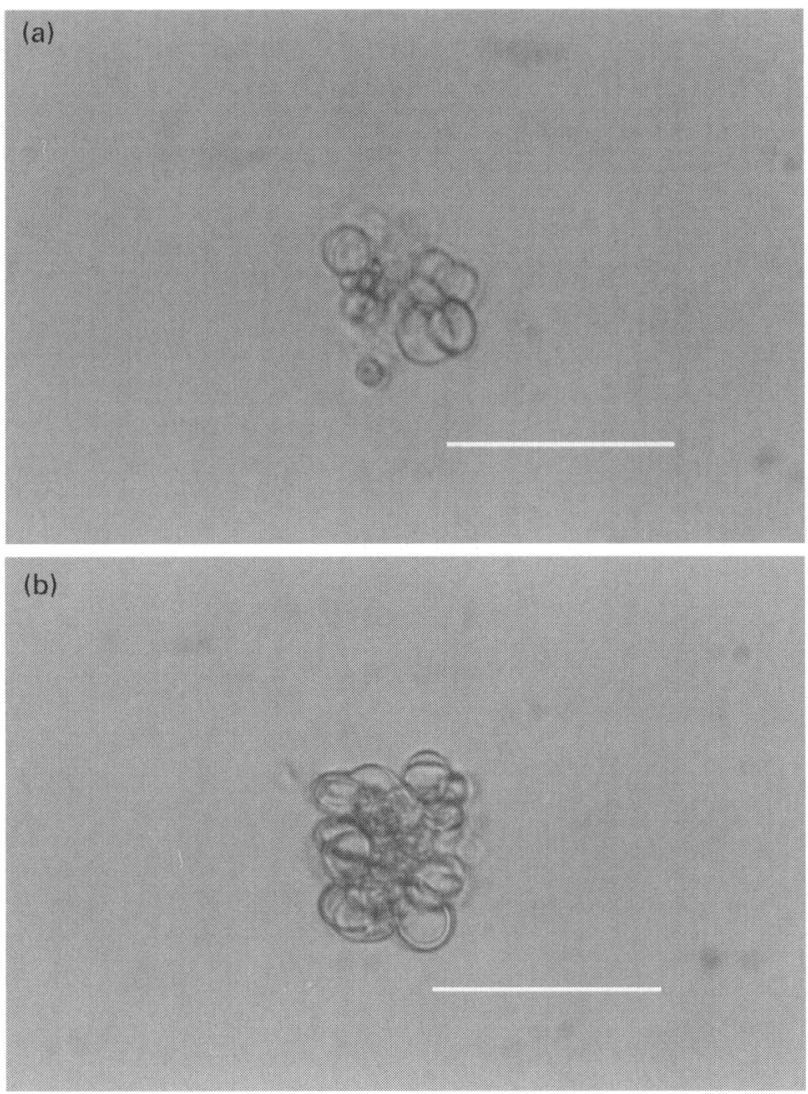

Fig. 4. Development of a single mouse gonocyte colony after (a) $24 \mathrm{~h}$ of culture compared with (b) 5 days of culture with stem cell factor and leukaemia inhibitory factor. Scale bars represent $50 \mu \mathrm{m}$.

\section{Effect of serum and growth factors on clonogenicity of gonocytes}

Gonocyte-derived colony formation was reliant on fetal calf serum in a dose-dependent manner and colonies were detected in $45-75 \%$ of wells (Fig. 8 ). The effect of various growth factors, individually and in combination, was studied to determine their influence on both clonogenicity and proliferation (number of cells per colony). When soluble SCF was added to cultures, mean colony formation was $81 \%$ (three experiments, 84 wells per group) compared with $82 \%$ without SCF. An antibody to SCF did not lower clonogenicity, indicating the SCF had a negligible contribution (Table 2). Mouse mast cells were used as the control for the effectiveness of anti-SCF antibody to block SCF action (Nocka ct al., 1990). Addition of anti-SCF resulted in a decrease in proliferation and $\left[{ }^{3} \mathrm{H}\right]$ thymidine was reduced from $4357 \pm$ 110 c.p.m. to $1688 \pm 121$ or $2299 \pm 398$ c.p.m. with anti-SCF alone or anti-SCF and SCF, respectively. The membranebound form of SCF was also tested for promotion of gonocyte-derived colony formation using STO cells. STO feeder layers produced $20 \pm 3.3 \%$ colony formation (Fig. 9) compared with $79 \pm 5.9 \%$ for cells cultured on collagen IVcoated wells (mean of five experiments). STO cells are known to produce both SCF and LIF. Soluble SCF and LIF were added to cultures and compared with cultures in which no

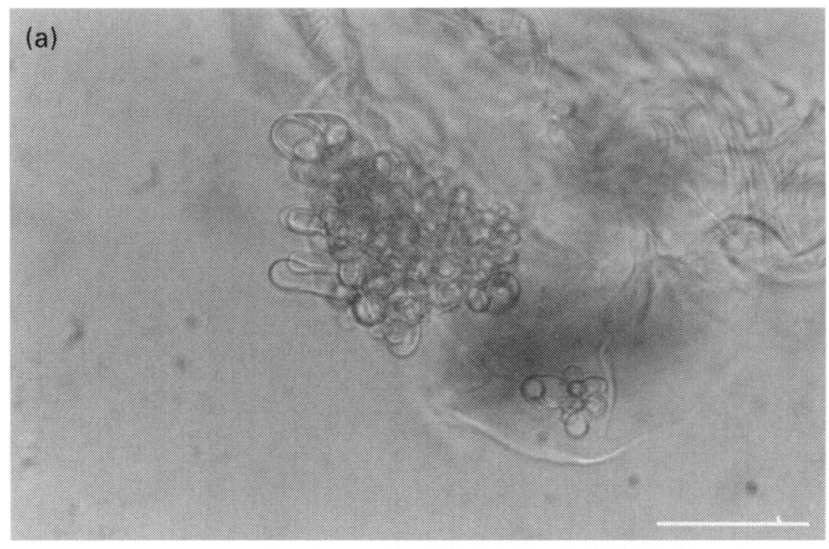

(b)

Fig. 5. Development of 5-day-old mouse gonocyte-derived colonies cultured without added growth factors showing elongated cells protruding from the colony periphery. Scale bars represent $50 \mu \mathrm{m}$.

factors were added to confirm that LIF did not have an inhibitory effect. Slightly higher numbers of colonies were obtained $(68 \pm 10.5 \%)$ compared with when no factors were added $(56 \pm 14.7 \%$ ) (mean of four experiments).

Addition of PDGF and SCF did not improve clonogenic capacity (Fig. 10), although with PDGF alone there was a shift in colony size to a modal value of $\geq 64-128$ cells compared with $\geq 16-64$ cells for SCF and PDGF or when no factors were added (Fig. 11). When LIF was added alone or in combination with SCF and PDGF, there was no effect on the incidence or size of colonies (data not shown).

$\mathrm{Li}$ et al. (1997) reported that $1 \mu \mathrm{mol}$ oestradiol $1^{-1}$ stimulated purified rat gonocytes to synthesize DNA and that this could be blocked by the oestrogen antagonist ICI 163384 . In the present study, oestradiol caused a small reduction in the number of colonies, as did the antagonist ICI 182,780 . Addition of both agents resulted in a number of colonies similar to that in control cultures (Fig. 12) and in all cases there was no shift in modal colony size.

\section{Discussion}

Newborn testis contains predominantly Sertoli cells, although 3-6\% of the tissue comprises gonocytes (Orth and 

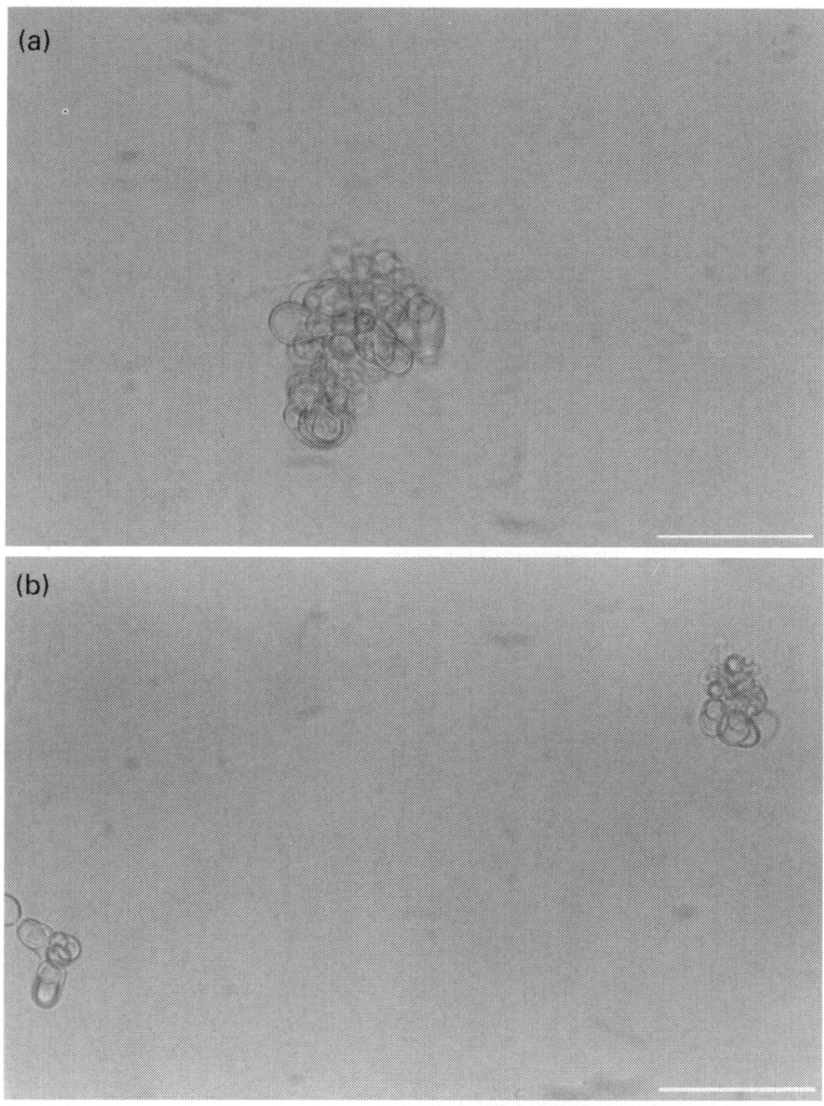

(c)

Fig. 6. Phenotype of mouse gonocyte-derived colonies after 4-5 days of culture without added factors. Examples of (a) compact, (b) dispersed and (c) matrix-associated colonies are shown. Scale bars represent $50 \mu \mathrm{m}$.

Boehm, 1990), Leydig, peritubular and interstitial cells that are integral to the testis microenvironment which supports spermatogenesis. Cellular interactions are important for testicular function, but it is very difficult to study germ cells in this complex tissue. Therefore, control of germ cell proliferation and differentiation has been examined in isolated cells in vitro. Co-cultures have established functional coupling of Sertoli and gonocyte cells with regard to growth factor interactions and physical properties (Orth and Boehm, 1990; de Miguel et al., 1996; van Dissel-Emiliani et al., 1996).

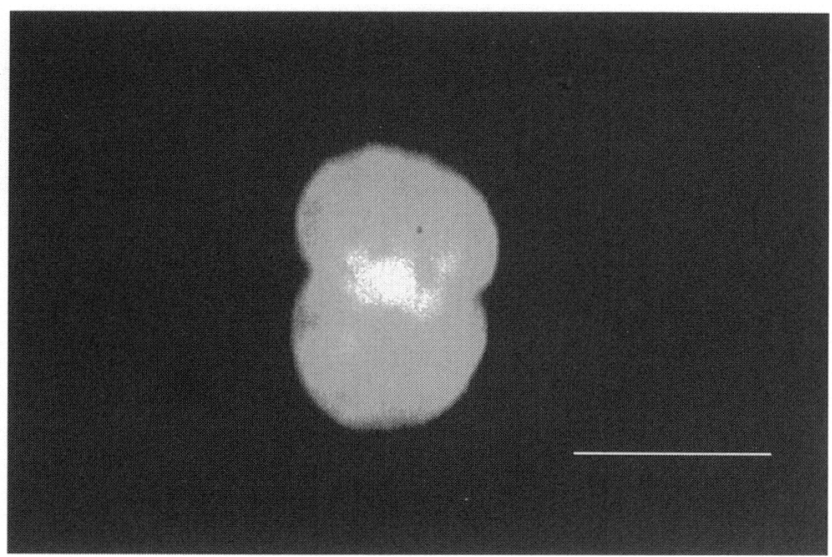

Fig. 7. Photomicrograph of mouse gonocyte-derived colony cells stained with the anti-germ cell nuclear antigen antibody observed under a fluorescence microscope. The nuclei only are visible. Scale bar represents $25 \mu \mathrm{m}$.

In the present study, gonocytes were studied in isolation from all other cells to determine the direct effects of growth promoting agents, including extracellular matrix. At birth, type IV collagen is detected in the continuous epithelial basement membrane of seminiferous cords (Gelly et al., 1989). Similarly, laminin lines the cords while fibronectin is more diffuse in the interstitial area. In the present study, collagen IV alone or with fibronectin enhanced the number and size (number of cells per colony) of gonocyte colonies in vitro, although the colonies were not firmly attached but were in contact with the extracellular matrix coating.

The growth characteristics and colony phenotype reflected some of the innate properties of gonocytes in vivo. A number of elongated cells were observed that were projecting away from the other cells in a migratory manner. The dispersed colony phenotype is presumably a result of such migratory gonocytes, which after initial proliferation move away and form new cell clusters. This property is apparent in vivo when gonocytes resume migration after birth to reach the periphery of the seminiferous tubule (McGuinness and Orth, 1992a). Re-initiation of cell division also occurs in neonatal rats from day 3 (McGuinness and Orth, 1992b) and mitotic gonocytes have been observed in vivo after birth in mice.

The critical events involved in resumption of germ cell proliferation after a period of mitotic arrest in developing testis are still unknown. However, proliferation is initiated within a few days of birth in vivo and is observed in vitro in co-culture experiments (van Dissel-Emiliani et al., 1996). Colony development in vitro showed gonocyte-derived cell clusters after $48 \mathrm{~h}$ of culture. The gonocyte population in newborn testis showed some diversity in the degree of proliferation; some colonies were $4-16$ cells and others contained $>128$ cells. The modal colony size was influenced by some of the growth factors, but when no factors were added there was still a wide range in colony size, indicating a different potential of gonocytes and their progeny for proliferation. The size of the cells in the colonies also 
Table 2. Effect of antibody to stem cell factor (SCF) on mouse gonocyte-derived colony growth and mast cell proliferation

\begin{tabular}{lcccc}
\hline Type of cell & SCF & anti-SCF antibody & SCF + anti-SCF antibody & None \\
\hline $\begin{array}{l}\text { Gonocyte-derived } \\
\text { colony formation }(\%)^{*}\end{array}$ & 92 & 90 & 94 & 88 \\
$\begin{array}{l}\text { Mast cells (c.p.m., } \\
{\left[{ }^{3} \text { H]thymidine) }\right.}\end{array}$ & $4357 \pm 110$ & $1688 \pm 121$ & $2299 \pm 398$ & $2712 \pm 1078$ \\
\hline
\end{tabular}

${ }^{*}$ Duplicate experiments, $12-18$ wells per group.

Duplicate experiments, mean \pm SEM of five replicates per group.

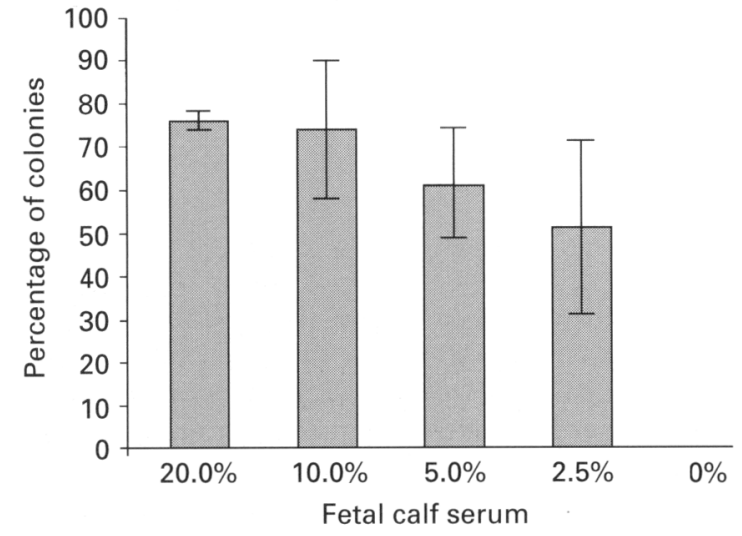

Fig. 8. Relationship between percentage of mouse gonocyte-derived colonies formed (mean $\pm \mathrm{SD}$ ) and concentration of fetal calf serum.

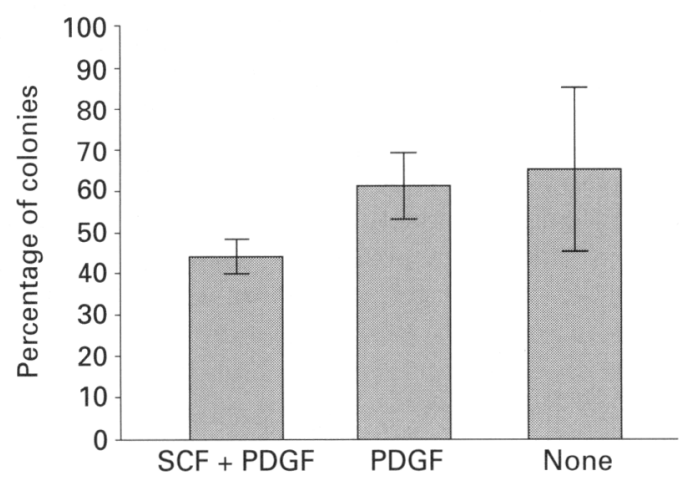

Fig. 10. Percentage of mouse gonocyte-derived colonies formed (mean \pm SD) in the presence of stem cell factor (SCF) and plateletderived growth factor (PDGF) or PDGF alone, or without added growth factors.

differed, which may be a reflection of cell cycle phase (G1 smaller than G2 cells) or differentiation of germ cells as colony formation takes place. Dispersed colonies usually comprised numerous clusters of a small number of cells, whereas matrix-associated colonies were typically very large. The matrix appeared to be synthesized by the germ
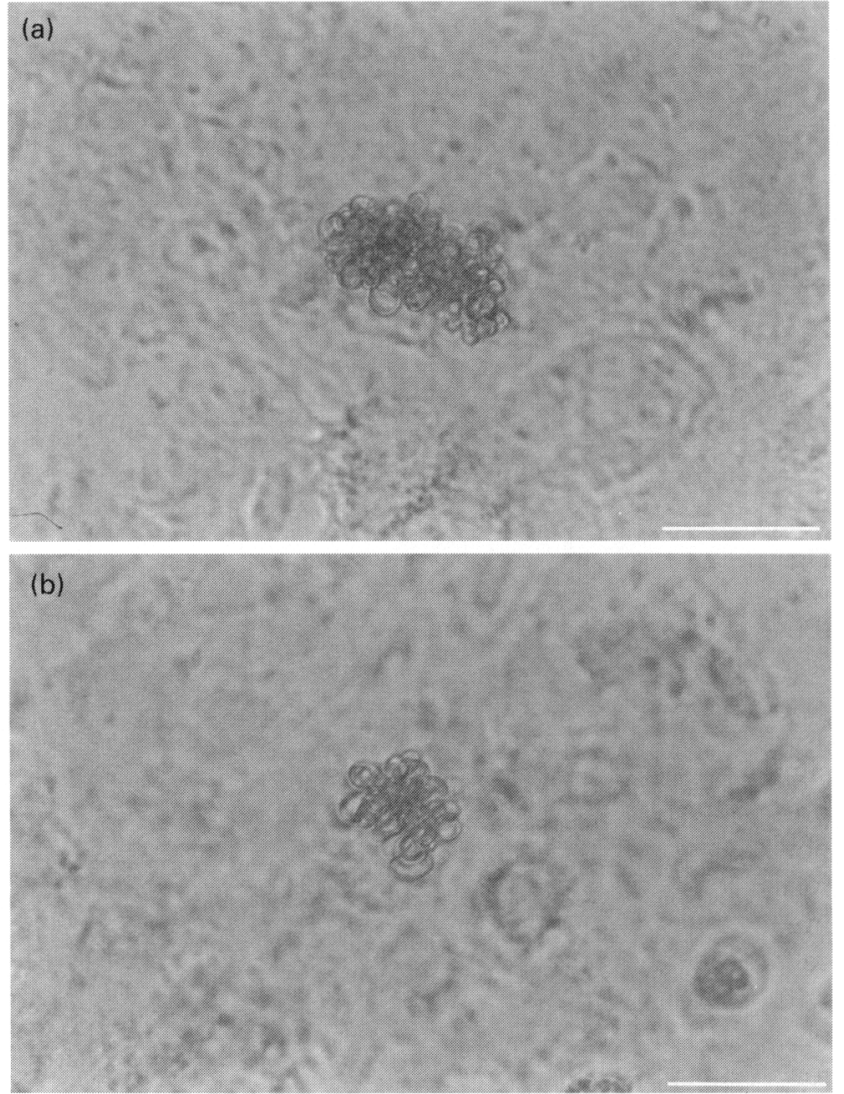

Fig. 9. Mouse gonocyte-derived colonies cultured without growth factors on STO feeder layers for 5 days. Scale bars represent $50 \mu \mathrm{m}$.

cells since it formed even when gonocytes were cloned on STO cell feeder layers or ECM-coated wells. The composition of this cell matrix is unknown, but may have some role in cell communication or may be an environmental factor.

SCF is a vital factor for the survival and maintenance of primordial germ cells in culture (Dolci et al., 1991) and acts synergistically with LIF to stimulate proliferation of primordial germ cells (Matsui et al., 1991). The entry of primordial germ cells into mitotic arrest may be correlated with a decrease in the expression of c-Kit (Manova et al., 1990) or an uncoupling of the receptor and intracellular 


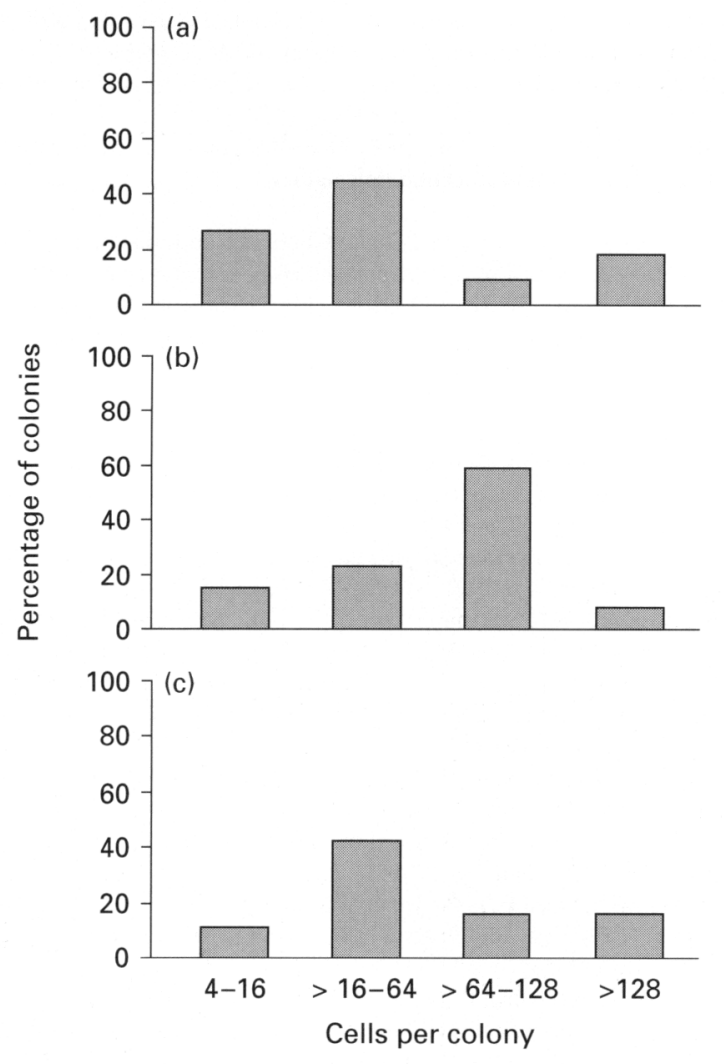

Fig. 11. Distribution of colony size of mouse gonocytes cultured with (a) stem cell factor (SCF) and platelet-derived growth factor (PDGF), (b) PDGF alone, or (c) without added growth factors.

signalling (Rottapel et al., 1991). The observations from the present study support the latter since the majority of newborn gonocytes expressed c-Kit, but optimal colony formation by gonocytes occurred without added soluble or membrane-bound SCF. Growth of colonies on STO feeder cells, which produce both SCF and LIF, was $22 \%$ compared with $79 \%$ when no factors were added. This inhibition may be due to LIF, but when LIF and SCF were added, colony formation was comparable with controls $(68 \pm 10.5 \%$ and $56 \pm 14.7 \%$, respectively). From these experiments, it is concluded that optimal colony formation occurred with FCS alone, that STO cell underlays gave suboptimal stimulation and soluble SCF did not increase colony formation. The PDGF receptor is expressed in rat gonocytes during the first 5 days after birth and purified gonocytes undergo a four-fold increase in the incorporation of bromodeoxyuridine when treated with PDGF in vitro (Li et al., 1997). In the present study, PDGF had little effect on the incidence of colonies, but was observed to increase the modal size of colonies and may act to enhance proliferation rather than initiate it in resting gonocytes.

The in vitro culture method described in this paper enabled growth factors and proliferation-inducing agents that affect gonocytes to be assayed directly. Isolation from secondary pathways that stimulate germ cell proliferation, such as paracrine effects from Sertoli and Leydig cells, is

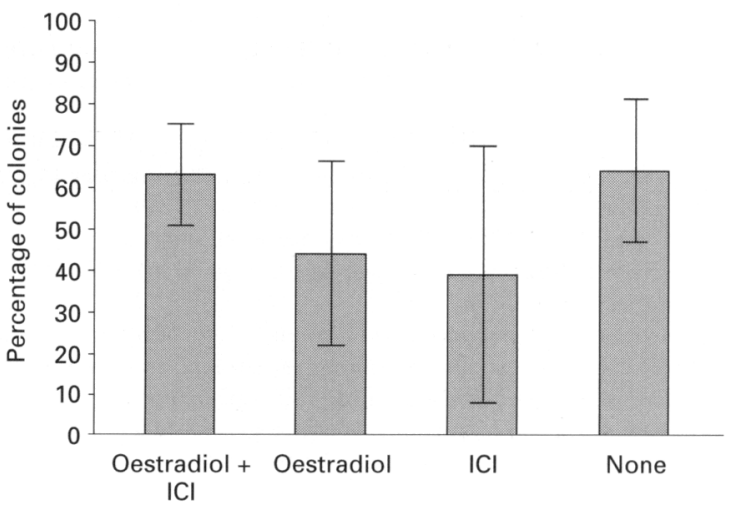

Fig. 12. Percentage of mouse gonocyte-derived colonies formed (mean $\pm \mathrm{SD}$ ) in the presence of oestradiol $\left(2 \mu \mathrm{mol} \mathrm{l}^{-1}\right)$, oestradiol antogonist ICI $182780\left(100 \mathrm{nmol} \mathrm{l}^{-1}\right.$; ICI), oestradiol and ICI 182780 , or without added growth factors.

crucial for establishing long-term culture of germ cells. The results of the present study indicate that certain properties of germ cells are expressed innately, even when isolated from the microenvironment of the testis. This was apparent from the elongation of colony cells and characteristic migratory behaviour displayed during colony development. Although this method promotes growth of germ cells, it raises the question of the nature of the growth regulatory molecules, since marked effects on proliferation were not observed with factors that are used routinely for propagation of primordial germ cells. ECM was essential for colony formation and indicates that this may be a crucial mechanism for signalling germ cell proliferation. Cell-cell interactions can also be studied in this assay by cell mixing experiments, as has been shown with STO cell underlays. In the future, this approach has the potential to unravel the differentiation and regulation of early germ cell development that occurs as the spermatogenic stem cell population is formed in the testis.

Supported by National Health and Medical Research Grant number 960128. The GCNA-1 antibody was a gift from G. Enders, University of Kansas Medical Center, Kansas City, KS, USA.

\section{References}

Clermont $Y$ and Perey B (1957) Quantitative study of the cell population of the seminiferous tubules in immature rats American Journal of Anatomy 100 241-268

De Miguel MP, de Boer-Brouwer M, Paniagua $R$, van den Hurk R, de Rooij DG and van Dissel-Emiliani FMF (1996) Leukemia inhibitory factor and ciliary neurotropic factor promote the survival of Sertoli cells and gonocytesin in a coculture system Endocrinology 137 1885-1893

Dissel-Emiliani FMF van, de Boer-Brouwer M, Spek ER, van der Donk JA and de Rooij DG (1993) Survival and proliferation of rat gonocytes in vitro. Cell and Tissue Research 273 141-147

Dissel-Emiliani van FMF, de Boer-Brouwer M and de Rooij DG (1996) Effect of fibroblast growth factor- 2 on Sertoli cells and gonocytes in coculture during the perinatal period Endocrinology $137647-657$

Dolci S, Williams DE, Ernst MK, Resnick JL, Brennan CI, Lock LF, Lymans SD, Boswell HS and Donovan PJ (1991) Requirement for mast cell growth factor for primordial germ cell survival in culture Nature 352 809-811

Edmondson SR, Werther GA, Russell D, Le Roith D, Roberts CT, Jr and 
Back F (1995) Localization of growth hormone receptor/binding protein messenger ribonucleic acid (mRNA) during rat fetal development: relationship to insulin-like growth factor-I mRNA Endocrinology 136 $4602-4609$

Enders GC and May JJ (1994) Developmentally regulated expression of a mouse germ cell nuclear antigen examined from embryonic day 11 to adult in male and female mice Developmental Biology 163 331-340

Friedrich G and Soriano P (1991) Promoter trap in embryonic stem cells: a genetic screen to identify and mutate developmental genes in mice Genes and Development 5 1513-1523

Gelly JL, Richoux JP, Leheup BP and Grignon G (1989) Immunolocalization of type IV collagen and laminin during rat gonadal morphogenesis and postnatal development of the testis and epididymis Histochemistry 93 31-37

Kierszenbaum AL (1994) Mammalian spermatogenesis in vivo and in vitro: a partnership of spermatogenic and somatic cell lineages Endocrine Revievos 15 116-135

Li H, Papadopoulos V, Vidic B, Dym M and Culty M (1997) Regulation of rat testis gonocyte proliferation by platelet-derived growth factor and estradiol: identification of signalling mechanisms involved Endocrinology 138 1289-1298

Loveland KL and Schlatt S (1997) Stem cell factor and c-kit in the mammalian testis: lessons originating from Mother Nature's gene knockouts Endocrinology 153 337-344

McGuinness MP and Orth JM (1992a) Gonocytes of male rats resume migratory activity postnatally European Journal of Cell Biology 59 196-210

McGuinness MP and Orth JM (1992b) Reinitiation of gonocyte mitosis and movement of gonocytes to the basement membrane in testes of newborn rats in vivo and in vitro. Anatomical Record 233 527-537

McLaren A (1983) Primordial germ cells in mice Bibliotheca Anatomy 24 59-66

McLaren A (1985) Mouse germ cells: fertilization to birth Archives Anatomical Microscopic Morphology 74 5-9

Manova K, Nocka K, Besmer P and Bachvarova RF (1990) Gonadal expression of c-kit encoded at the $\mathrm{W}$ locus of the mouse Development 110 1057-1069

Matsui Y, Toksoz D, Nishikawa S, Nishikawa S-I, Williams D, Zsebo K and Hogan BLM (1991) Effect of Steel factor and leukaemia inhibitory factor on murine primordial germ cells in culture Nature 353 750-752

Munsie M, Schlatt S, de Kretser DM and Lakoski-Loveland K (1997) Expression of stem cell factor in the postnatal rat testis Molecular Reproduction and Development 47 19-25

Nocka K, Buch J, Levi E and Besmer P (1990) Candidate ligand for the c-kit transmembrane kinase receptor: $\mathrm{KL}$, a fibroblast derived growth factor stimulates mast cells and erythroid progenitors EMBO Journal $93287-3294$

Orth JM and Boehm R (1990) Functional coupling of neonatal rat Sertoli cells and gonocytes in coculture Endocrinology 127 2812-2820

Orth JM and McGuinness MP (1991) Neonatal gonocytes co-cultured with Sertoli cells on a laminin-containing matrix resume mitosis and elongate Endocrinology 129 1119-1121

Orth JM, Jester WF, Jr and Qui J (1996) Gonocytes in testes of neonatal rats express the c-kit gene Molecular Reproduction and Development 45 123-131

Orth JM, Qiu J, Jester WF, Jr and Pilder S (1997) Expression of the c-kit gene is critical for migration of neonatal rat gonocytes Biology of Reproduction $\mathbf{5 7}$ $676-683$

Paranko J (1987) Expression of type I and III collagen during morphogenesis of fetal rat testis and ovary Anatomical Record 219 91-101

Pelliniemi LJ, Paranko J, Grund SK, Frojdman K, Foidart JM and LakkalaParanko T (1984) Extracellular matrix in testicular differentiation Annals New York Academy of Science 438 405-416

Robertson EJ (1985) Teratocarcinomas and embryonic stem cells. In A Practical Approach Series pp 71-112 Ed EJ Robertson. IRL Press, Washington DC

Rottapel R, Reedijk M, Williams DE, Lyman SD, Anderson DM, Pawson T and Bernstein A (1991) The Steel/W transduction pathway: kit autophosphorylation and its association with a unique subset of cytoplasmic signaling proteins is induced by the Steel factor Molecular and Cellular Biology 11 3043-3051

Russo VR, Edmondson SR, Mercuri FA and Werther GA (1994) Identification, localization, and regulation of insulin-like growth factor binding proteins and their messenger ribonucleic acids in the newborn rat olfactory bulb Endocrinology 135 1437-1446

Sawada H and Yazama F (1994) Type IV collagen in the rat testis: monoclonal antibody, isolation and localization during development Biology of Reproduction 50 702-710

Skinner MK, Tung PS and Fritz IB (1985) Cooperativity between Sertoli cells and testicular peritubular cells in the production and deposition of extracellular matrix components Journal of Cellular Biology 100 1941-1947

Ware LM and Axelrad AA (1972) Inherited resistance to N- and B-tropic murine leukemia viruses in vitro: evidence that congenic mouse strains SIM and SIM R differ at the Fv-1 locus Virology 50 339-348

Yoshinaga K, Nishikawa S, Ogawa M, Hayashi S-I, Kunisada T, Fujimoto T and Nishikawa S-I (1991) Role of c-kit in mouse spermatogenesis: identification of spermatogonia as a specific site of $c-k i t$ expression and function Development 113 689-699 